\title{
Effect of Solution Treatment on Age-Hardening Behavior of Al-12Si-1Mg-1Cu Piston Alloy with Trace-Zr Addition
}

\author{
Mohammad Salim Kaiser* \\ Bangladesh University of Engineering and Technology, Directorate of Advisory, Extension and Research Services, Dhaka-1000, Bangladesh \\ *e-mail: mskaiser@iat.buet.ac.bd
}

Received: 17 February 2018/Accepted: 3 April 2018/Published online: 26 June 2018

This article is published with open access at AGH University of Science and Technology Press

\begin{abstract}
The influence of a solution treatment with a trace zirconium addition on the precipitation behavior of a cast $\mathrm{Al}-12 \% \mathrm{Si}-1 \% \mathrm{Mg}$ $1 \% \mathrm{Cu}$ piston alloy has been reported. The alloys were prepared by controlled melting and casting. The cast alloys were given an age-hardening treatment having a sequence of homogenization, T6 solutionizing, quenching, and aging. Both the cast and solutionized samples were naturally aged for 58 days, isochronally aged for 60 minutes at different temperatures (up to $350^{\circ} \mathrm{C}$ ), and isothermally aged at various temperatures (up to $225^{\circ} \mathrm{C}$ ) for different periods of time (ranging from 15 to 360 minutes). The hardness values of the differently processed alloys were measured to understand the aging behavior of the alloys. Electrical resistivity changes with aging time and temperature were measured to understand the precipitation behavior of the alloys. It is observed that significant hardening takes place in the aged alloys due to the formation of GP zones as well as the formation of metastable phases. The solutionizing treatment improves the hardness because some alloying elements are re-dissolved during solution treatment to produce a solute-rich solid solution. The trace-added $\mathrm{Zr}$ hinders the softening due to the precipitation of $\mathrm{Al}_{3} \mathrm{Zr}$, which is very stable against coarsening and the re-dissolution of precipitates. Electrical resistivity decreases due to stress relieving, the dissolution of the metastable phase, and precipitation coarsening. The resistivity of the solutionized alloys decreases more due to the higher concentration of elements in the solid solution. A microstructural study of the alloys reveals that the solution treatment improves the distribution of the silicon grains. It is also observed that the alloys attained an almost fully re-crystallized state after aging at $350^{\circ} \mathrm{C}$ for 90 minutes.
\end{abstract}

\section{Keywords:}

Al-Si alloys, trace addition, solutionizing, age hardening, resistivity

\section{INTRODUCTION}

Al-Si casting alloys have been widely used as piston materials in light vehicle engines because of their excellent mechanical properties. To ensure the adequate high-temperature mechanical performance, alloying elements such as $\mathrm{Cu}, \mathrm{Ni}, \mathrm{Mg}, \mathrm{Fe}$, etc. are traditionally added to strengthen the piston alloys by the formation of numerous precipitates [1]. Precipitation hardening (also called age hardening) is a heat-treatment technique used to increase the mechanical properties of these aluminum alloys [2]. The age hardening-treatment procedure consists of three major steps: solution treatment, rapid cooling (quenching), and aging. Solution treatment involves keeping the alloy at a temperature higher than the solvus temperature but lower than the liquidus temperature for a period of time to homogenize one phase of the solid solution (where the solute atoms are dissolved completely in the solution). A rapid cooling or quenching of the solid solution is carried out in a medium such as water, oil, or even air. During this step, the solute atoms are not allowed to move and form an $\alpha$-phase, so they stay dissolved in a supersaturated phase. Finally, during the aging stage, the alloy hardness starts to increase when the solute atoms start to diffuse as clusters that distort and strengthen the material. Al-Si cast alloys are intended to be used at temperatures lower than $225^{\circ} \mathrm{C}$. Above this temperature, the microstructure-strengthening mechanisms of these alloys tend to become unstable [3, 4]. It has been reported earlier that the strength of Al-Si alloys falls beyond $225^{\circ} \mathrm{C}$ due to precipitation coarsening. This also leads to a change in the microstructure of these alloys [5]. The addition of transition elements such as zirconium (which forms trialuminides with low solubility and a low diffusion coefficient) provides a very useful instrument in the control of the aluminum alloy microstructure. The small precipitates formed by adding small quantities of $\mathrm{Zr}$ develop a large coarsening resistance in the matrix along with high thermal stability due to their higher melting point in respect to the matrix [6]. With a $\mathrm{Zr}$ concentration of more than $0.1 \%, \mathrm{Al}_{3} \mathrm{Zr}$ particles forms from the melt as a primary phase during rapid solidification and act as nuclei for the solidification of $\mathrm{Al}$; thus, $\mathrm{Zr}$ can function as a grain refiner of $\mathrm{Al}[7,8]$.

In view of the potential of zirconium as a recrystallization inhibitor and grain refiner in aluminum and its alloys, the present investigation mainly aims at the development of 
a new class of $\mathrm{Al}-12 \mathrm{Si}-1 \mathrm{Mg}-1 \mathrm{Cu}-0.024 \mathrm{Zr}$ alloys that will be more versatile than the existing alloys.

\section{EXPERIMENTAL PROCEDURE}

The melting was carried out in a resistance heating furnace under the suitable flux cover (degasser, borax, etc.). First, the commercially used aluminum pistons were melted in a clay-graphite crucible (which was used as the master alloy). Two heats were taken for developing an $\mathrm{Al}$ 12Si-1Mg-1Cu base alloy, and Al-12Si-1Mg-1Cu containing zirconium. Zr was taken in the form of a powder $(99.98 \%$ purity) within a cover of aluminum foil and was then added by plunging. The final temperature of the melt was always maintained at $750 \pm 15^{\circ} \mathrm{C}$. The casting was done in a cast iron metal mold preheated to $200^{\circ} \mathrm{C}$. Mold sizes were $16 \times$ $150 \times 300$ millimeters. The alloy was simultaneously analyzed by the wet chemical and spectrochemical methods. The chemical composition of the alloy is given in Table 1 . A portion of the cast alloys were homogenized in a Muffle furnace at $400^{\circ} \mathrm{C}$ for 18 hours and air cooled to relieve the internal stresses and for homogenization. The homogenized samples were solutionized at $530^{\circ} \mathrm{C}$ for 2 hours followed by salt ice water quenching to get a super-saturated single-phase region. The cast and solutionized alloys were cut to pieces of $15 \times 15 \times 5 \mathrm{~mm}$. The samples were subjected to (i) natural aging for 58 days, (ii) isochronal aging for 60 minutes at different temperatures up to $350^{\circ} \mathrm{C}$, and (iii) isothermal aging at various temperatures up to $250^{\circ} \mathrm{C}$ for different periods of time (ranging from 15 to 360 minutes). The age-hardening behavior was followed by hardness measurements. A Rockwell F scale (60 kg load, 1/16" steel ball indenter) was used, and an average of ten concordant readings were taken as the representative hardness of a sample. The electrical conductivity of the alloys in the as-cast and solutionized conditions were carried out with an electric conductivity meter (type 979). The $15 \mathrm{~mm} \times 15 \mathrm{~mm}$ size finished surface samples produced by grinding and polishing were prepared for this measurement. The electric resistivity was calculated from the conductivity data. Specimens of the cast and heat-treated cast alloys were subjected to optical metallographic studies. The specimens were polished with alumina, etched with Keller's reagent, and observed under a Versamet-II Microscope. The SEM of the selected samples was carried out by a Jeol Scanning Electron Microscope (type JSM-5200).

\section{RESULTS AND DISCUSSION}

\subsection{Age-hardening behavior}

\section{Natural aging}

Figure 1 shows the variation of hardness among cast Alloy 1(AC), cast trace-Zr-added Alloy 2(AC), solution-treated Alloy 1(ST), and trace-Zr-added solution-treated Alloy 2(ST) under natural aging conditions.

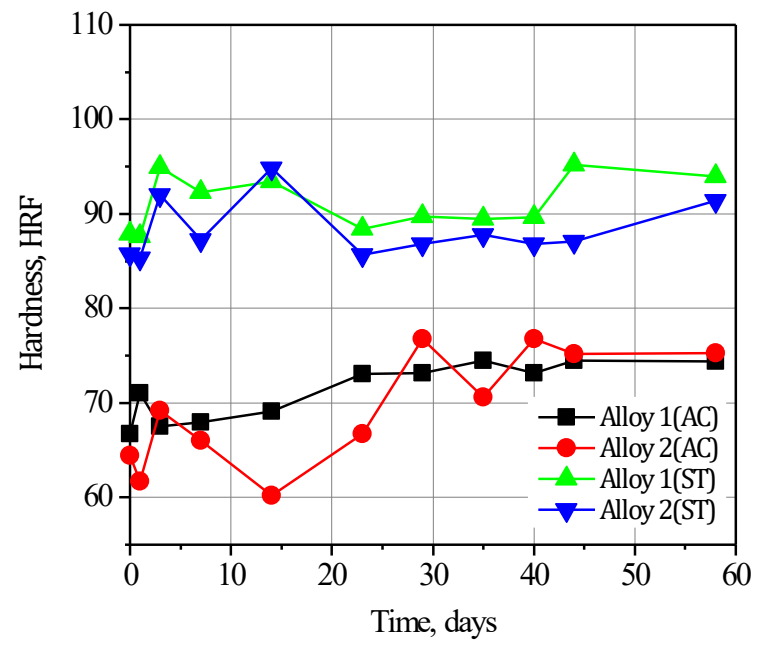

Fig. 1. Natural aging curves of alloys for 58 days

It is apparent that all of the alloys achieved some extent of age hardening. This is due to the formation of hexagonal Mg2Si. Clusters of solute atoms form in the matrix during natural aging, consuming both solute atoms and vacancies. However, solution-treated Alloy 1(ST) and Alloy 2(ST) initially showed higher hardness. During solution treatment at $530^{\circ} \mathrm{C}$ for two hours, some alloying elements are re-dissolved to produce a solute-rich solid solution. This is to maximize the concentration of the hardening elements (including copper, zinc, magnesium, and silicon) in the solid solution.

Table 1

Chemical composition of the experimental alloys (wt.\%)

\begin{tabular}{cccccccccc}
\hline & $\mathbf{S i}$ & $\mathbf{M g}$ & $\mathbf{C u}$ & $\mathbf{N i}$ & $\mathbf{F e}$ & $\mathbf{M n}$ & $\mathbf{T i}$ & $\mathbf{Z r}$ & $\mathbf{A l}$ \\
\hline Alloy 1 & 12.280 & 0.919 & 1.120 & 1.306 & 0.521 & 0.038 & 0.061 & 0.001 & Balance \\
\hline Alloy 2 & 12.410 & 0.938 & 1.130 & 1.328 & 0.554 & 0.043 & 0.064 & 0.024 & Balance \\
\hline
\end{tabular}

Remarks:

Alloy 1(AC) - Al-12Si-1Mg-1Cu (as-cast)

Alloy 2(AC) - Al-12Si-1Mg-1Cu-0.024Zr (as-cast)

Alloy 1(ST) - Al-12Si-1 Mg-1Cu (solution-treated)

Alloy 2(ST) - Al-12Si-1Mg-1Cu-0.024Zr (solution-treated) 
The cast alloy is slowly cooled from an elevated temperature, alloying the elements to precipitate and diffuse from the solid solution to concentrate at the grain boundaries, at the small voids, on the undissolved particles, at the dislocations, and on the other imperfections in the aluminum lattice [2]. The trace-Zr-added alloys (both the cast and solution-treated alloys) are delayed to attain age hardening. The addition of $\mathrm{Zr}$ leads to the formation of L12-orderd Al3Zr trialuminide particles from the melt and hinder to dislocation movement. Consequently, these precipitates are very effective in pinning the grain and sub-grain boundaries during all of the thermal and mechanical processing of the aluminum alloys [9].

\section{Isochronal aging}

Figure 2 shows the hardness variation in the isochronal aging conditions of cast Alloy 1(AC), trace-Zr-added Alloy 2(AC), solution-treated Alloy $1(\mathrm{ST})$, and trace-Zradded solution-treated Alloy 2(ST) at different temperatures for 60 minutes. It can be seen that the pattern with two aging peaks is clear for all of the alloys (as reported earlier) [10-12]. The increase in hardness at the initial stage of the aging process continues until it reaches the first peak. Then, a little decrease in the hardness of each is shown, and the hardness increases again to reach the second peak. At the last stage of aging, they each follow a sharp decrease in hardness due to over-aging effects.

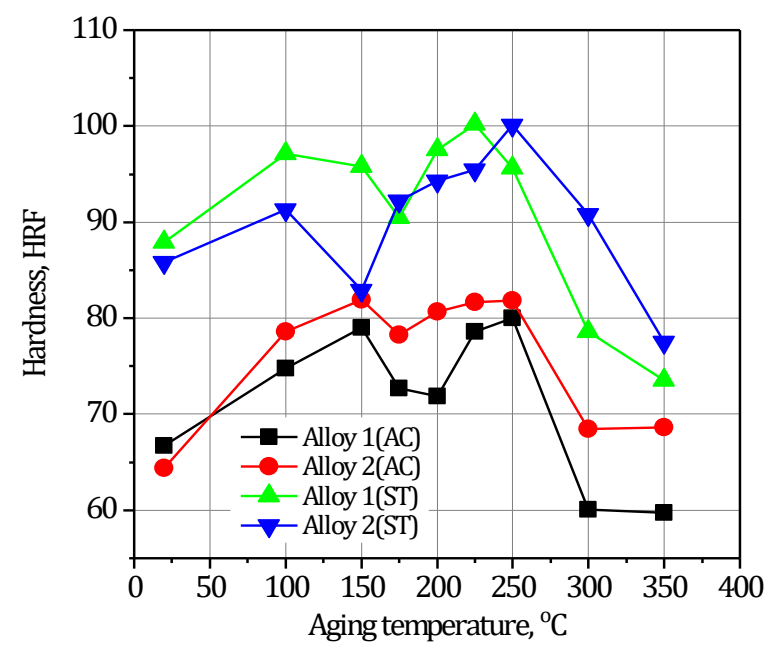

Fig. 2. Isochronal aging curves of alloys aged for one hour

In the age-hardening process of the alloys, the GP zones and metastable phases can effectively strengthen the alloys and lead to the aging peak. In the early stages of aging, fine and profuse GP zones homogeneously distribute in the matrix; then, their effects on strengthening are significant. On the other hand, the metastable phases formed at the intermediate stage of aging and kept semi-coherence with the matrix are effectively resistant to the movement of dislocation; thus, have a certain strengthening effect [13]. However, these GP zones remarkably dissolve before metastable-phase formation in the precipitation sequence of the alloys. It has been reported that the $\theta$ phase had been observed to have nucleated on dislocation [12]. In the stage of transition from GP zones to metastable phases, the number of GP zones decreases significantly for dissolution, while the metastable precipitates have not grown; their size is too small to effectively resist the movement of dislocation. Therefore, the age-hardening effect of the alloy must be low at this stage, and it can be presumed that the stage of GP-zone dissolution should be responsible for the aging value between the two aging peaks of the alloys. The softening of the alloys at higher temperatures may be due to the particle coarsening effect as well as recrystallization. In both the as-cast and solution-treated alloys, the trace-Zr-added alloys show relatively higher strengths at higher aging temperatures. The addition of $\mathrm{Zr}$ leads to the formation of the $\mathrm{L}_{2}$-orderd $\mathrm{Al}_{3} \mathrm{Zr}$ phase during the solution heat treatment as well as from the melt. These particles are coherent and thermally stable because of their high melting points (as compared to that of the Al matrix). Also, the $\mathrm{Al}_{3} \mathrm{Zr}$ particles provide strong obstacles for the dislocation movement. As a result, these precipitates are very effective in pinning the grain and sub-grain boundaries during all thermal and mechanical processing of the aluminum alloys [9].

Figure 3 shows the electrical resistivity of the alloys and their derivative with respect to the temperature for one hour. The initial drop in resistivity is due to the stress relieving in the alloys during aging. Transition metals are known to strongly bind the vacancies [14]. For this reason, the number density of the scattering centers is reduced; this causes a fall in resistivity. The subsequent increase in resistivity is due to the appearance of fine precipitates. The steep drop in the resistivity of the alloys is considered to be due to the recovery of the strain or dissolution of the metastable phases already present in the matrix. From the resistivity curve, the initial resistivity of the solution-treated alloys shows a higher value than that of the cast alloys, and the resistivity of the solutionized alloys decreases more due to the higher concentration of elements in the solid solution.

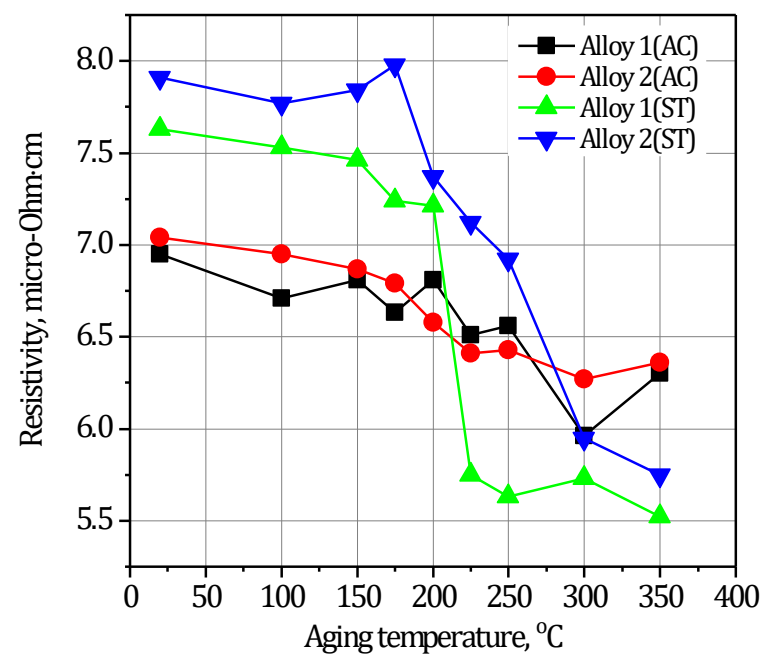

Fig. 3. Variation of resistivity of alloys isochronally aged for one hour 
The trace-Zr-added alloys delayed due to the precipitation of $\mathrm{Al}_{3} \mathrm{Zr}$, which are very stable against the coarsening and re-dissolution of the precipitates [9].

\section{Isothermal aging}

Figures 4-7 show the variations of hardness of the cast Alloy 1(AC), trace-Zr-added Alloy 2(AC), solution-treated Alloy 1(ST), and solution-treated trace-Zr-added Alloy 2 (ST) isothermally aged at $175,200,225$, and $250^{\circ} \mathrm{C}$ for different times, respectively. It can be found that the double aging peaks are present for all of the alloys, and higher hardness was attained. The age-hardening peaks are correlated to their precipitation sequences. The first hardness peak is attained depending on the high-density GP zones, while the second one is acquired in terms of the metastable particles. An obvious interval during the transition from the GP zone to the metastable phase (which is caused by dissolution of the GP zone and nucleation of the metastable phase on dislocation) may be the main reason for the formation of double aging peaks [10]. At the final stage of aging at higher temperatures, the hardness decreases due to over-aging as well as precipitation coarsening. From the isothermal age-hardening curves, it is shown that the Zr-free alloys attained the maximum hardness at relatively low aging temperatures and less time. On the other hand, the trace-Zr-added alloys attained the maximum hardness when aged at $225^{\circ} \mathrm{C}$ for 90 minutes. Both the trace-Zr-added and solution-treated alloys are most effective in suppressing the softening effect during prolonged aging treatment. The zirconium additions form $\mathrm{Al}_{3} \mathrm{Zr}$; they have low solubilities and a low diffusion coefficient in the aluminum matrix. They maintain a small lattice mismatch with the matrix, reducing the interfacial energy between the matrix and the precipitates. As a result, the precipitates present a large coarsening resistance in the matrix and, additionally, increased thermal stability because of their high melting points (as compared to that of the aluminum matrix) [6].

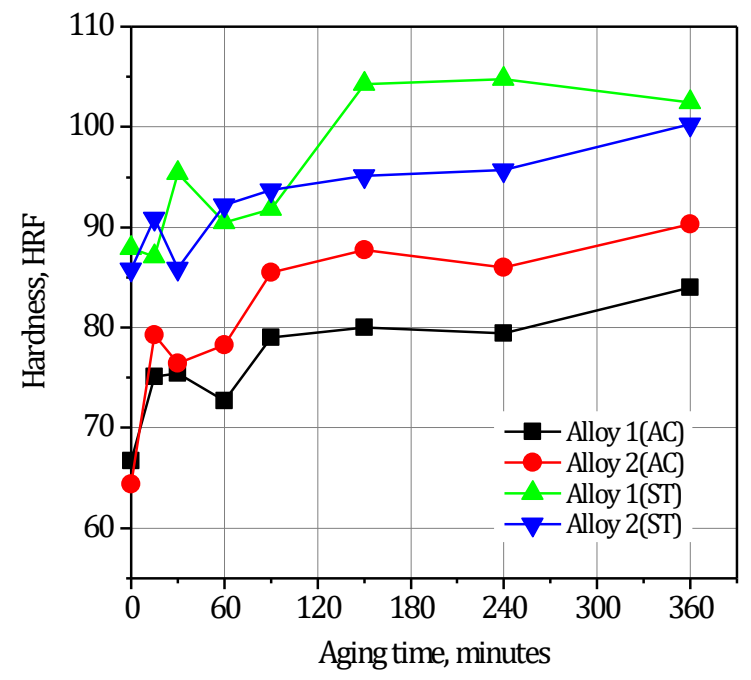

Fig. 4. Isothermal aging curves of alloys aged at $175^{\circ} \mathrm{C}$

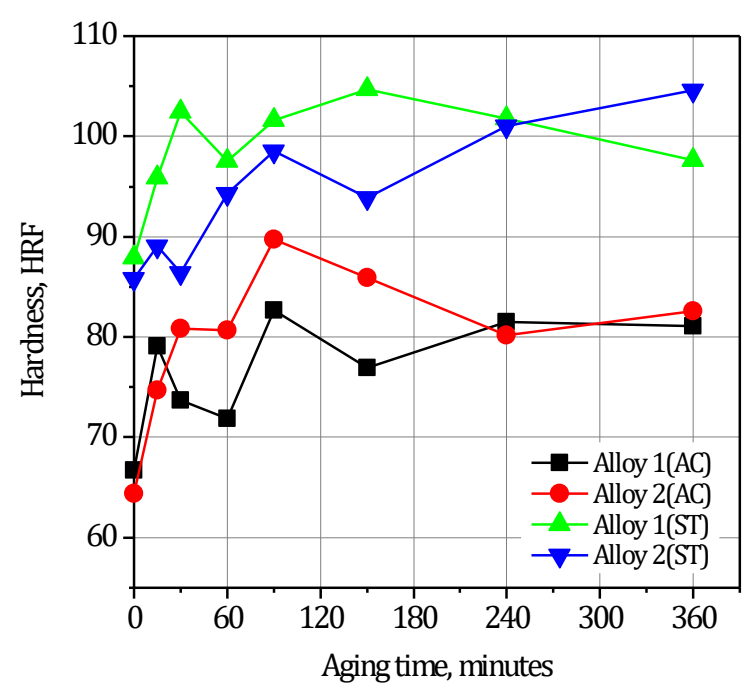

Fig. 5. Isothermal aging curves of alloys aged at $200^{\circ} \mathrm{C}$

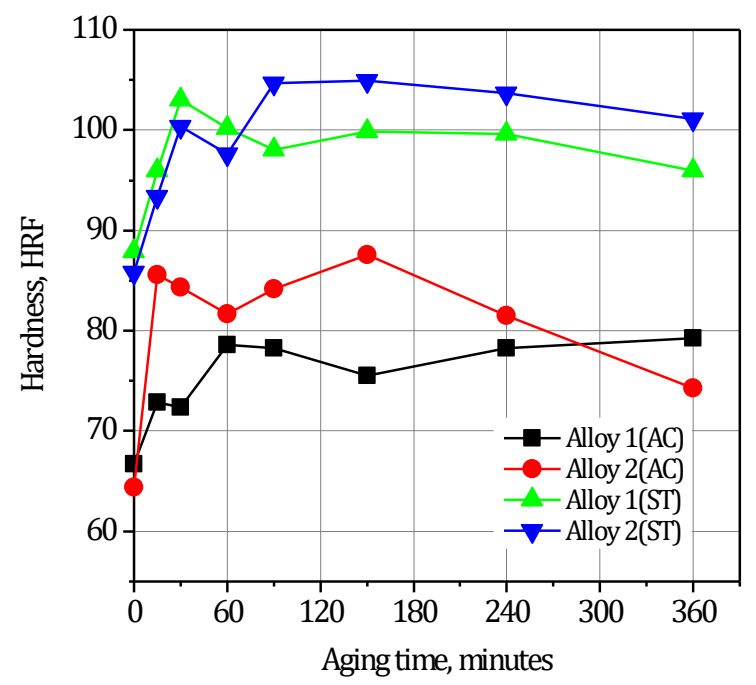

Fig. 6. Isothermal aging curves of alloys aged at $225^{\circ} \mathrm{C}$

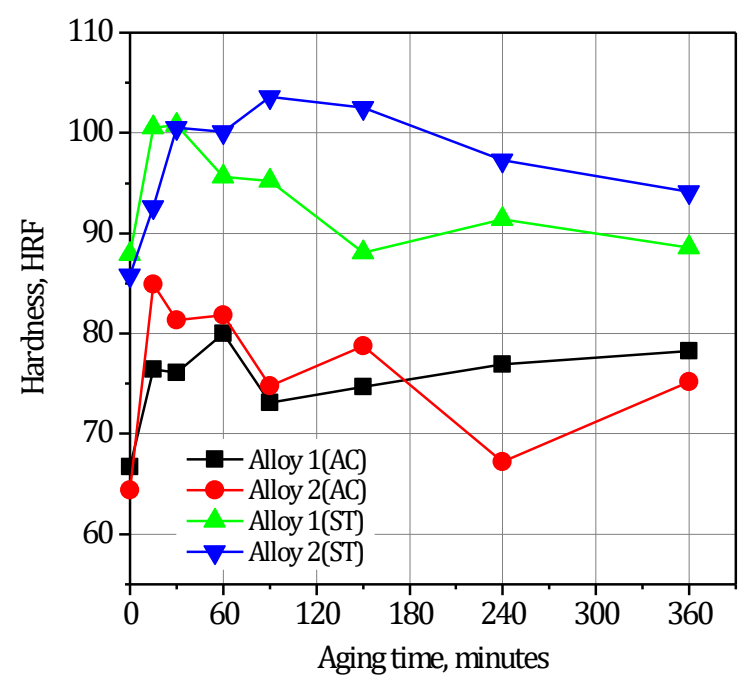

Fig. 7. Isothermal aging curves of alloys aged at $250^{\circ} \mathrm{C}$ 
The resistivity values of the alloys isothermally aged at different temperatures show a general trend of their decrease (Figs. 8-11). The rate of decreasing resistivity depends on increasing temperatures. However, a small increase in the resistivity of the alloys is noted within 60-90 minutes of aging. Then, the resistivity remains more or less constant. The resistivity curves for isothermal aging at higher temperatures show a steep drop in the initial period, followed by a peak. This observation is general for all of the alloys (although the magnitude of variation is noted to be different for the as-cast and solution-treated alloys). The steeper drop in resistivity at the initial period of isothermal aging may be attributed to the formation of a solute atom vacancy complex. For this reason, the number density of the scattering centers is reduced. This causes a sharp fall in resistivity. The subsequent increase in resistivity is due to the appearance of fine precipitates. When the aging temperature is low, the resistivity continues to increase beyond the peak because the precipitation formation and reordering of atoms continues. The steep drop in resistivity is considered to be due to the recovery of the strain or dissolution of the metastable phase already present in the matrix. This reasons out the dissolution of the $\beta$ precipitate; hence, strain recovery is supposedly the responsible factor for the above drop in resistivity. From the resistivity curves, the initial resistivity of solution-treated Alloy 1(ST) and Alloy 2(ST) show higher values than that of cast Alloy 1(AC) and Alloy 2(AC). Solution treatment produces a supersaturated solid solution and refines the grains, which affects the resistivity. The sharp decrease in resistivity is found to be much higher in solution-treated Alloy $1(\mathrm{ST})$ and Alloy 2(ST) than in cast Alloy 1(AC) and Alloy 2(AC). The resistivity of the cast alloy remains fairly unaltered over the entire period of aging. At the final stage of aging, resistivity decreases due to the coarsening of the precipitates and recrystallization. The trace-Zr-added alloys delayed this process due to the formation of $\mathrm{Al}_{3} \mathrm{Zr}$ trialuminide particles (which are resistant to coarsening), giving rise to some good thermal stability of the microstructure [15].

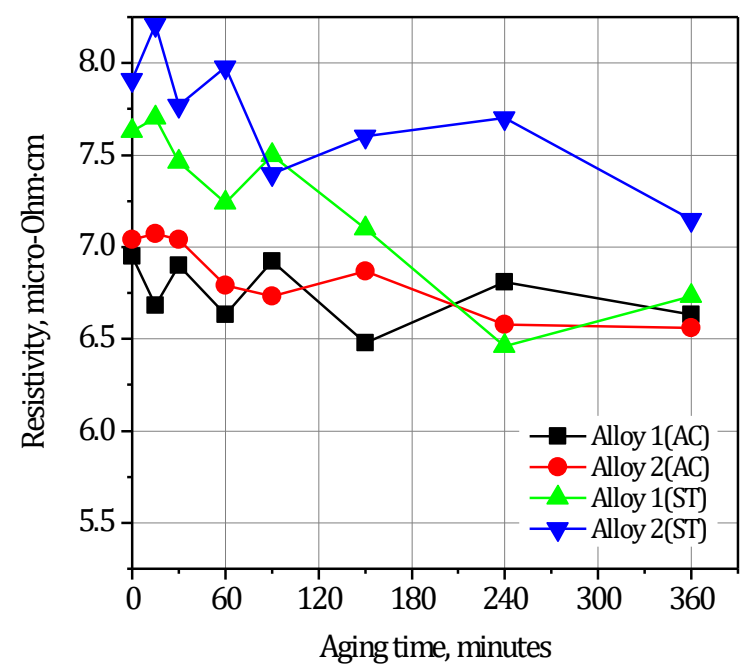

Fig. 8. Variation of resistivity of alloys with time isothermally aged at $175^{\circ} \mathrm{C}$

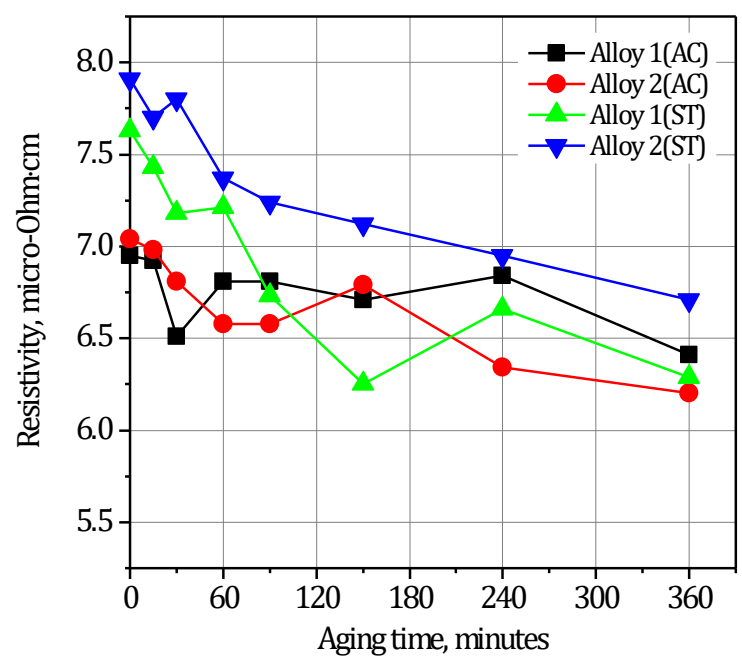

Fig. 9. Variation of resistivity of alloys with time isothermally aged at $200^{\circ} \mathrm{C}$

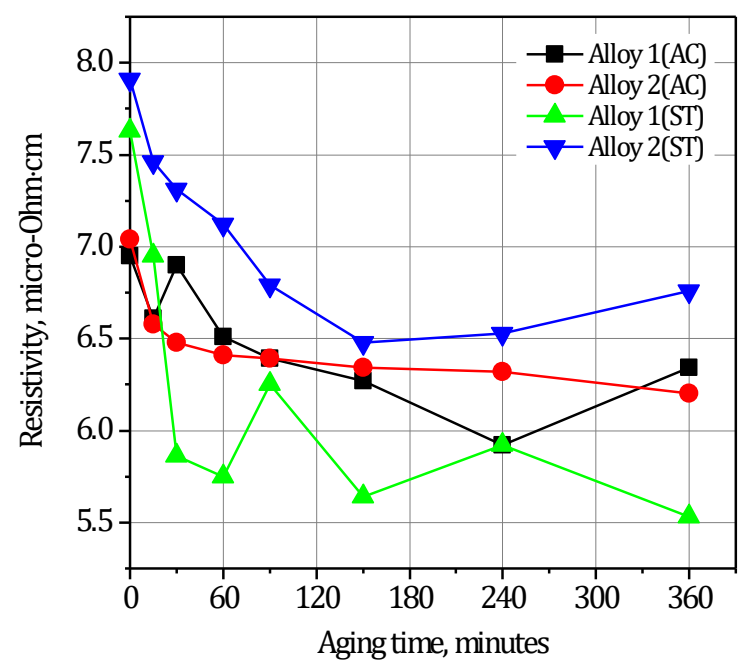

Fig. 10. Variation of resistivity of alloys with time isothermally aged at $225^{\circ} \mathrm{C}$

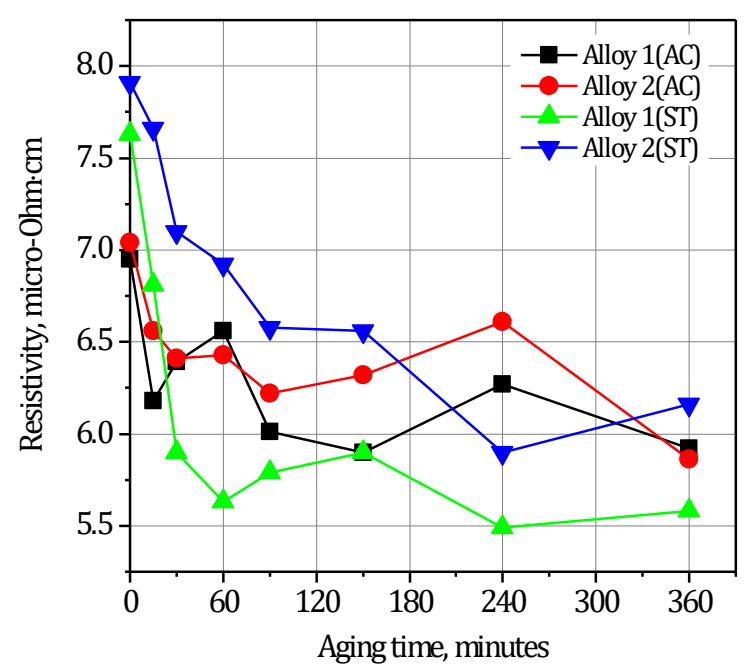

Fig. 11. Variation of resistivity of alloys with time isothermally aged at $250^{\circ} \mathrm{C}$ 


\section{Optical microscopy}

Figures $12 \mathrm{a}$ and $12 \mathrm{~b}$ show the optical microstructure of as-cast Alloy 1(AC) and trace-Zr-added cast Alloy 2(AC), which consisted of the eutectic $\mathrm{Si}, \mathrm{Ni}_{3} \mathrm{Al}, \mathrm{Mg}_{2} \mathrm{Si}$, and Fe-rich intermetallic phases on the $\alpha$-Al matrix. It should be noted that the sample was produced by the non-modification and rapid solidification in the cast iron mold. It can be seen that the eutectic Si phase is flake-like and has acicular morphologies. After two hours of solution treatment at $530^{\circ} \mathrm{C}$, the eutectic silicon was clearly fragmented and

a)

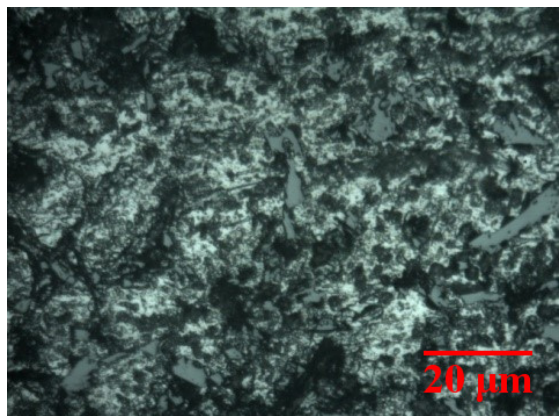

b)

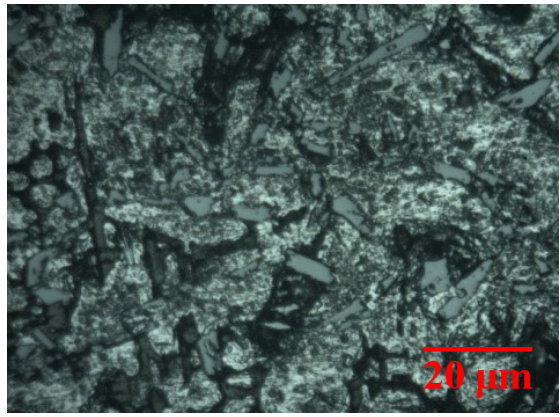

c)

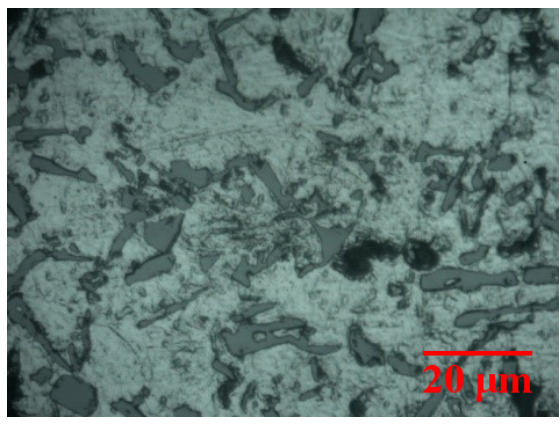

d)

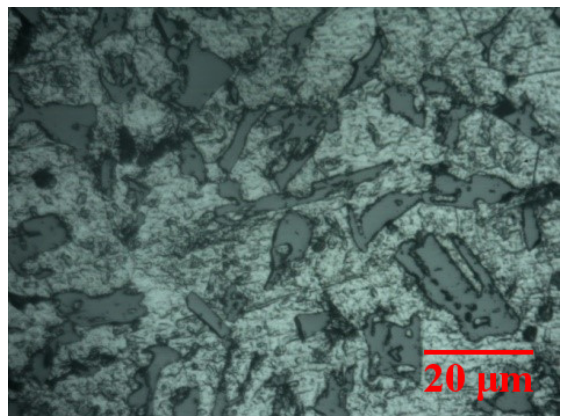

Fig. 12. Microstructure of $\mathrm{Al}-12 \mathrm{Si}-1 \mathrm{Mg}-1 \mathrm{Cu}$ piston alloys: a) cast Alloy 1(AC); b) trace-Zr-added Alloy 2(AC); c) solution-treated Alloy 1(ST); and d) trace-Zr-added solution-treated Alloy 2(ST) more spherical (as shown in Figures 12c and 12d). The silicon particle became coarser, and the inter-particle spacing was increased. However, the uniform distribution of particles can be clearly observed from the solution-treatment samples. Moreover, it was found that the $\mathrm{NiAl}_{3}$ phase was also dissolved by the solution-treatment time. Trace-Zr-added Alloy 2(AC) and Alloy 2(ST) showed relatively finer grains because $\mathrm{Zr}$ refines the grain structure of the aluminum alloys [8]. If the alloys are aged at $350^{\circ} \mathrm{C}$ for 60 minutes, they is seen to be recrystallized almost fully (Fig. 13).

a)

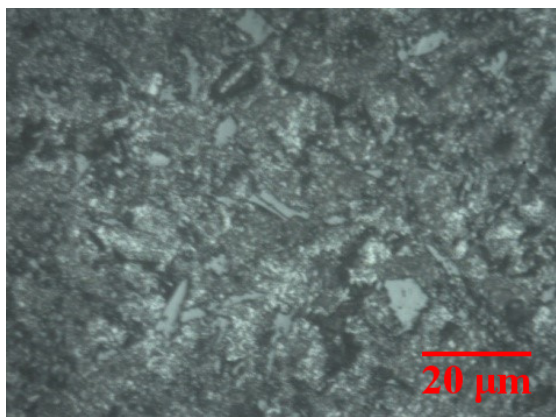

b)

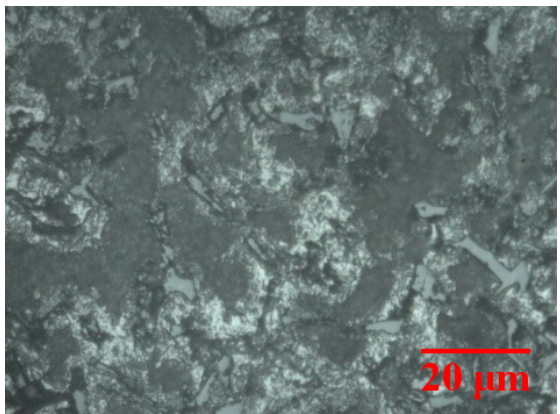

c)

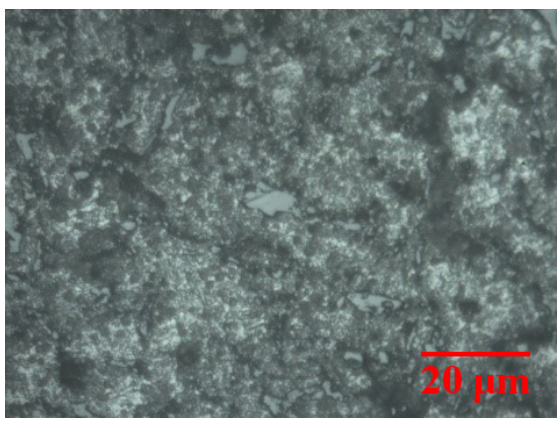

d)

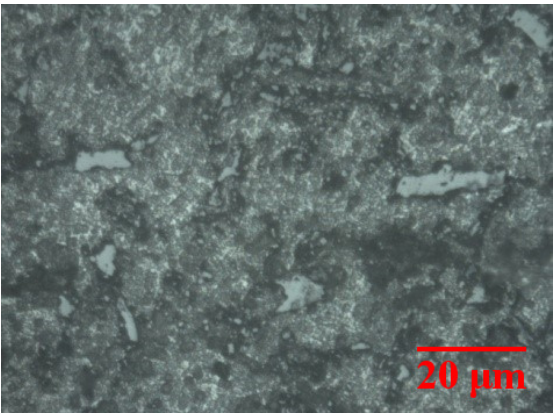

Fig. 13. Microstructure of $\mathrm{Al}-12 \mathrm{Si}-1 \mathrm{Mg}-1 \mathrm{Cu}$ piston alloys aged at $350^{\circ} \mathrm{C}$ for 60 minutes: a) cast Alloy $1(\mathrm{AC})$; b) trace-Zr-added cast Alloy 2(AC); c) solution-treated Alloy 1(ST); and d) trace-Zr-added solution-treated Alloy 2(ST) 
At higher temperatures, recrystallization took place. The dendrites seem to be dissolved, and precipitation coarsening occurred. As a result, the microstructure consisted of equi-axed grains [11].

\section{Scanning electron microscopy}

Figure 14 shows the SEM microstructures of cast Alloy 1(AC), trace-Zr-added Alloy 2(AC), solution-treated Alloy 1(ST), and trace-Zr-added solution-treated Alloy 2(ST) after artificial aging at $225^{\circ} \mathrm{C}$ for 90 minutes. The microstructures consisted mainly of a primary $\mathrm{Al}$ dendrite, eutectic $\mathrm{Si}, \mathrm{Al}_{15}(\mathrm{Fe}, \mathrm{Mn})_{3} \mathrm{Si}_{2}, \mathrm{Mg}_{2} \mathrm{Si}$, and a few numbers of Fe-rich intermetallic phases on the $\alpha$-Al matrix in the inter-dendritic region. A number of voids and cavities can be seen in the microstructure of the alloys. Two types of $\mathrm{Al}_{3} \mathrm{Ni}$ phases are the plate-like and needlelike morphologies [11]. The features of the microstructures of the alloy in T6 condition undergo changes upon heat treatment. Microstructural observation shows that the secondary arm spacing is reduced for the solution-treated alloys. Most of the intermetallic phases are partially dissolved and tend to spherodize; i.e., the sharp corners have become rounded. The morphology change of the eutectic Si is obvious after heat treatment. The changes in the size and morphology of the discontinuous silicon phase are significant since they have a direct influence on the mechanical properties.

a)

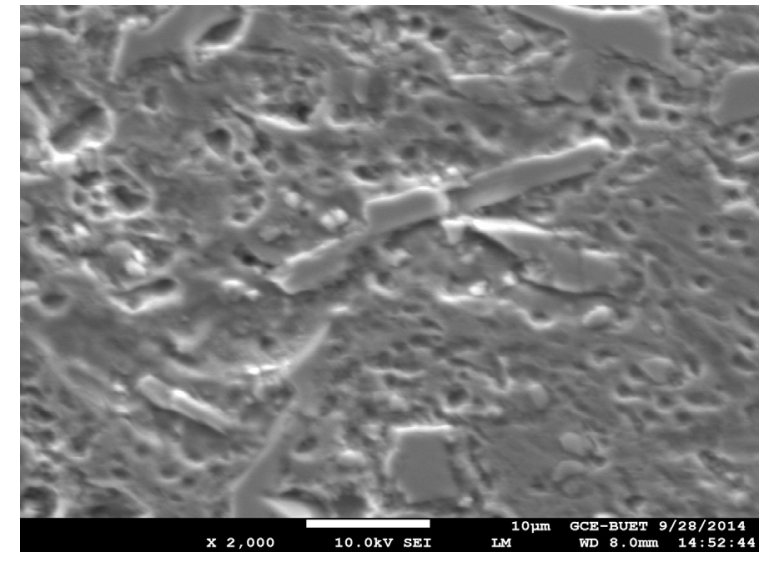

c)

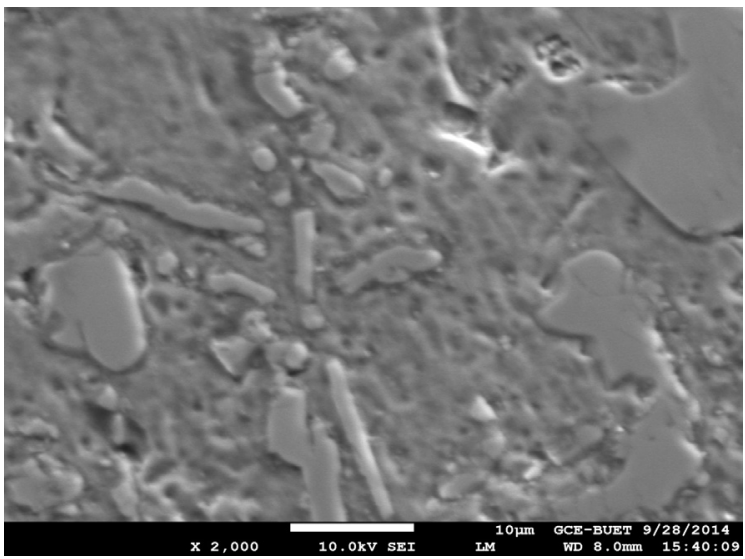

After artificial aging treatment for all of the alloys at $225^{\circ} \mathrm{C}$ for 90 minutes, precipitation occurred within the matrix; however, the precipitates cannot be revealed by these types of images [16]. The trace-Zr-added alloys show a relatively finer grain because $\mathrm{Zr}$ acts as the nuclei for solidifying the alloys [8].

\section{CONCLUSIONS}

Solution treatment of the $\mathrm{Al}-12 \% \mathrm{Si}-1 \% \mathrm{Mg}-1 \% \mathrm{Cu}$ piston alloy has strong effects on both the morphology and particle distribution of the eutectic Si. In the age-hardening curve of the alloys, double aging peaks are present. The first hardness peak of the age-hardening curve is attained depending on the high-density GP zones, while the second one is acquired in terms of the metastable particles. During aging, electrical resistivity decreases due to stress relieving, dissolution of the metastable phase, and precipitation coarsening; it is found to be higher in the solution-treated alloys due to the higher volume fraction of the precipitates. Trace-added $\mathrm{Zr}$ refines the grain structure and hinders the softening due to the precipitation of $\mathrm{Al}_{3} \mathrm{Zr}$, which is very stable against coarsening, re-dissolution, and pin-grain boundaries. The eutectic silicon was clearly fragmented and more spherical in the solution-treated alloys. Both the cast and solution-treated alloys are seen to be recrystallized almost fully after aging at $350^{\circ} \mathrm{C}$ for 60 minutes.

b)

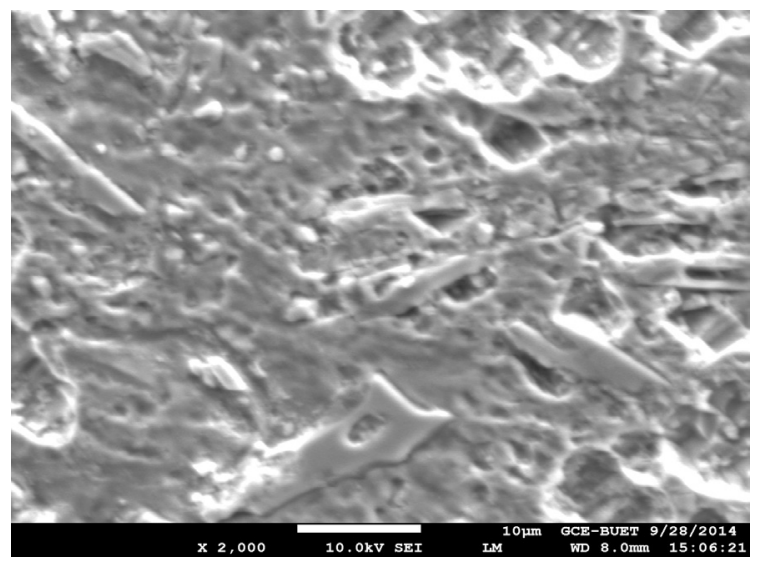

d)

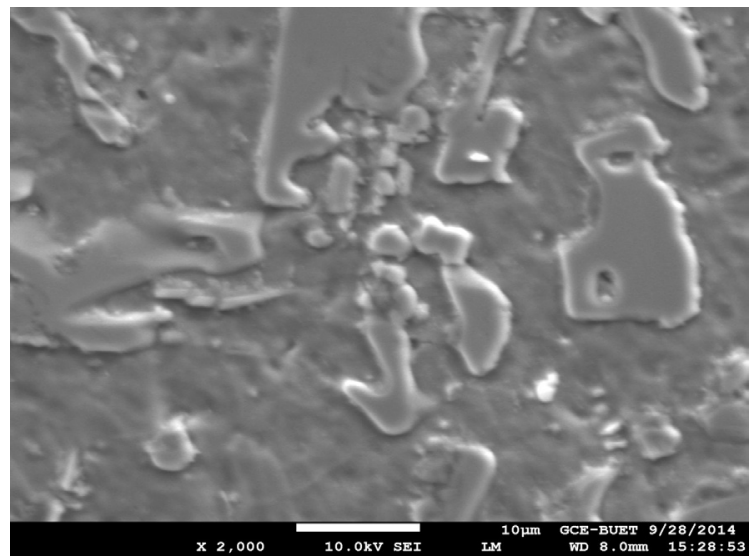

Fig. 14. SEM images of Al-12Si-1Mg-1Cu piston alloys aged at $225^{\circ} \mathrm{C}$ for 90 minutes: a) cast Alloy $1(\mathrm{AC})$; b) trace-Zr-added Alloy 2(AC); c) solution-treated Alloy 1(ST); and d) trace-Zr-added solution-treated Alloy 2(ST) 


\section{Acknowledgements}

This work is supported by CASR of Bangladesh University of Engineering and Technology and is part of the "Effect of trace zirconium on the chemical, electrical, mechanical and physical properties of cast and heat-treated aluminum-silicon piston alloy" project. Thanks to the Department of Glass and Ceramics Engineering for providing the laboratory facilities.

\section{REFERENCES}

[1] Li Y., Yang Y., Wu Y., Wang L. \& Liu X. (2010). Quantitative comparison of three $\mathrm{Ni}$-containing phases to the elevated-temperature properties of Al-Si piston alloys. Materials Science and Engineering A, 527, 7132-7137.

[2] Mbuya T.O., Sinclair I., Moffat A.J. \& Reed P.A.S. (2011). Analysis of fatigue crack initiation and S-N response of model cast aluminium piston alloys. Materials Science and Engineering A, 528, 7331-7340.

[3] Hamasha M.M., Mayyas A.T., Hassan A.M. \& Hayajneh M.T. (2012). The effect of time, percent of copper and nickel on naturally aged Al-CuNi. Journal of Minerals \& Materials Characterization and Engineering, 11(2), 117-131.

[4] Kaiser M.S. \& Kurny A.S.W. (2011). Effect of scandium on the grain refining and ageing behaviour of cast Al-Si-Mg alloy. Iranian Journal of Materials Sciences and Engineering, 8(4), 1-8.

[5] Zhanga G., Li B., Zhang J., Feng Z., Wei Z. \& Cai W. (2012). Unique cyclic deformation behavior of a heavily alloyed Al-Si piston alloy at different temperatures. Progress in Natural Science: Materials International, 22(5), 445-451.

[6] Yin Z., Pan Q., Zhang Y. \& Jiang F. (2002). Effect of minor Sc and $\mathrm{Zr}$ on the microstructure and mechanical properties of Al-Mg based alloys. Materials Science and Engineering A, 280, 151-155.
[7] Waheed A. \& Lorimer G.W. (1997). Pinning of subgrain boundaries by $\mathrm{Al}_{3} \mathrm{Zr}$ dispersoids during annealing in $\mathrm{Al}$-Li commercial Alloys. Journal of Materials Science Letters, 16, 1643-1646.

[8] Seong S.I., Han S.Z., Choi S.K. \& Lee H.M. (1996). Phase Equilibria of $\mathrm{Al}_{3}(\mathrm{Ti}, \mathrm{V}, \mathrm{Zr})$ Intermetallic System. Scripta Materialia, 34(11), 1697-1704.

[9] Spigarelli S., Cabibbo M., Evangelista E. \& Bidulska J. (2003). A study of the hot formability of an Al-Cu-Mg-Zr alloy. Journal of Materials Science, 38, 81-88.

[10] Shivkumar S., Keller C. \& Apelian D. (1990). Aging behavior in cast Al-Si-Mg alloys. AFS Transactions, 98, 905-911.

[11] Zhang D.L. \& Zheng L. (1996). The quench sensitivity of cast Al-7 wt pct Si-0.4 wt pct Mg alloy. Metallurgical and Materials Transactions A, 27(12), 3983-3991.

[12] Kang H.K., Kida M. \& Miyahara H. (1999). Age hardening characteristics of Al-Si-Cu-Base cast alloys. AFS Transactions, 107, 507-515.

[13] Kashyap K.T., Murali S., Raman K.S. \& Murthy K.S.S. (1993). Casting and heat treatment variables of Al-7Si-Mg alloy: Overview. Material Science and Technology, 9, 189-203.

[14] Bo N., Zhi-min Y. Da-peng Z. Yong-yi P. Feng J. \& Ji-wu H. (2007). Effect of homogenization treatment on microstructure and properties of Al-Mg-Mn-Sc-Zr alloy. Journal of Central South University of Technology, 14(4), 452-455.

[15] Kaiser M.S. (2011). Grain refinement and precipitation hardening of cast $\mathrm{Al}-6 \mathrm{Mg}$ alloy through ternary scandium and quaternary zirconium and titanium addition. International Journal of Research in Mechanical Engineering and Technology, 1(1), 57-62.

[16] Ma A., Saito N., Shigematsu I., Suzuki K., Takagi M., Nishida Y., Iwata H. \& Imura T. (2004). Effect of heat treatment on impact toughness of aluminum silicon eutectic alloy processed by rotary-die equal-channel angular pressing. Materials Transactions, 45(2), 399-402. 